\title{
Child feeding knowledge and practices among women participating in growth monitoring and promotion in Accra, Ghana
}

\author{
Sandra Gyampoh ${ }^{1 *}$, Gloria Ethel Otoo ${ }^{1}$ and Richmond Nii Okai Aryeetey ${ }^{2}$
}

\begin{abstract}
Background: Child undernutrition and poor feeding practices remain a concern in Ghana. The Growth Monitoring and Promotion (GMP) programme seeks to empower mothers to provide appropriate child care. Although the program has been implemented in Ghana for over four decades, little is known about its impact on child feeding outcomes. The current study assessed the association between GMP exposure and mothers' child feeding knowledge and practices in the Accra Metropolitan Area (AMA), Ghana.
\end{abstract}

Methods: A cross-sectional survey of 199 mother-child pairs accessing child welfare services in six public health facilities in the AMA was conducted. A structured questionnaire was used to collect data on respondent characteristics and child feeding knowledge; a 24-hour dietary recall tool was used to record child feeding practices. Linear regression analysis was used to determine the association between mothers' exposure to GMP and their knowledge and practices on child feeding.

Results: Seventy four percent of mothers had not missed any scheduled child welfare clinic sessions. Over $60 \%$ of mothers knew the appropriate age of introduction of foods; $86 \%$ also gave correct response regarding minimum number of times their child should be fed daily. About $81 \%$ of children less than 6 months were exclusively breastfed in the preceding 24 hours, although 36\% had received water since birth. Forty two percent of children 6-23 months received dietary diverse meals while $64 \%$ were fed the required number of times in a day. Overall, only $32 \%$ of children 6-23 months received a minimum acceptable diet in the preceding 24 hours. A higher GMP exposure was positively associated with feeding knowledge scores among mothers with children below 6 months $(p<0.05)$.

Conclusion: Although most mothers were knowledgeable about recommendations, feeding practices were suboptimal, especially complementary feeding. GMP exposure was associated with feeding knowledge only among mothers with children less than 6 months. Strengthening of feeding counselling focused on children above 6 months is recommended.

Keywords: Growth monitoring and promotion, Child welfare clinic, Child feeding, Complementary feeding, Breastfeeding

\section{Background}

An estimated 35\% of global under-five deaths, and 50-70\% of diarrhoeal diseases, measles, malaria and lower respiratory infections in developing countries are attributable to child undernutrition [1,2]. Undernourished children are prone to poor mental, physical and physiological development, and are at increased risk of infections and death

\footnotetext{
* Correspondence: sandragyampoh@yahoo.com

'Department of Nutrition and Food Science, University of Ghana, Legon, P.O. Box LG 134, Accra, Ghana

Full list of author information is available at the end of the article
}

due to nutrient deficiencies [2,3]. In Ghana, the latest Multiple Indicator Cluster Survey [4] shows that about $13 \%$ of children below age 5 years are underweight, 23\% are stunted, and $6 \%$ are wasted. In the Greater Accra Region (GAR), underweight is found among $8.3 \%$ of children $0-5$ years while $13.7 \%$ and $5.4 \%$ are stunted and wasted respectively [4].

Undernutrition is often common in poor-resource countries where appropriate breastfeeding and complementary feeding (CF) practices are suboptimal [5-8]. Usually, complementary foods are introduced too early

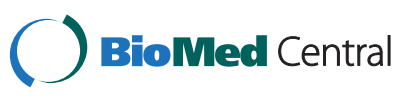


and are often of poor quality and quantity in terms of nutrient diversity, density and feeding frequency $[5,9]$. In Ghana, only $46 \%$ of children below six months are exclusively breastfed. In the GAR of Ghana, only $21.1 \%$ of children between 0-5 months were exclusively breastfed, being the lowest rate recorded in the country. Often, the diet of Ghanaian children is mainly made of grains, roots and tubers $[4,10]$. Improving child feeding practices among mothers therefore remains essential to improving child nutrition and survival in Ghana.

The Ghana Health Service's Child Welfare Clinic (CWC) is a comprehensive child health service that includes immunization, nutrient supplementation, and growth monitoring and promotion. The Growth Monitoring and Promotion (GMP) component of the CWC is focused on empowering mothers to know about and become competent to practice appropriate child care, feeding, and health seeking. These outcomes are pursued using individualized and group counselling $[11,12]$. The GMP provides an opportunity for interaction between public health workers and mothers regarding the health and wellbeing of their children [13].

Although the GMP program has been implemented in Ghana for over four decades [14], little is known about its impact on child feeding outcomes. A previous study in Ghana reported on mothers' comprehension of growth charts used as part of the GMP to monitor child growth patterns as well as factors influencing mother's attendance to CWC [14]. The current study assessed the association between GMP exposure and mothers' knowledge and practices on the feeding of their young children under two years in the Accra Metropolitan Area of Ghana.

\section{Methods}

\section{Study sites}

The study was carried out in six public health facilities, one in each of the six health sub-metropolitan areas in the Accra Metropolitan Area (AMA) of Ghana. The AMA is the most densely populated administrative district in the Greater Accra region with an estimated 4.5 million people living in the capital city of Accra. The Metropolitan area is sub-divided into six sub metros: Kpeshie, Osu-Clottey, Okaikoi, Ayawaso, Ablekuma and Ashiedu-Keteke.

\section{Study design and participants}

The study used a cross-sectional design and surveyed 199 mother-child pairs accessing CWC services in the selected health facilities. This sample size was adequate to detect a $15 \%$ difference in prevalence of maternal knowledge across regular and non-regular CWC attendees at a power of $80 \%$ and confidence level of $95 \%$ [15].

One health facility was randomly selected from a list of public-managed health facilities in each sub-metropolitan area. The number of mother-child pairs recruited from each health facility was proportional to the number of children below 24 months enrolled in the particular facility as at June 2011. Data for the study were collected between November 2011 and January 2012.

The study protocol was approved by the Institutional Review Board of the Noguchi Memorial Institute for Medical Research (NMIMR-IRB), University of Ghana. The AMA as well as the selected facilities provided documented approval to facilitate work at each selected study site. Mother-child pairs attending monthly CWC sessions were approached and recruited into the study after informed consent was obtained between November 2011 and February 2012. Inclusion criteria were mothers with children aged 0-23 months, of normal birth weight $(\geq 2.5 \mathrm{~kg})$, of singleton birth and with no obvious signs of illness.

\section{Study questionnaire \\ Background characteristics}

A structured questionnaire was used to record data on socio-demographic characteristics of mother-child pairs and child feeding knowledge and practices of mothers. The number of CWC attended was obtained from child health records. Interviews were conducted individually with the assistance of a trained field assistant.

\section{Child feeding knowledge}

To assess mothers' child feeding knowledge, a questionnaire previously used in Haiti was adapted [16] based on recommended feeding practices [17]. Questions covered the appropriate age of introduction of water and other liquids, grains/roots and tubers, vegetables, fruits, dairy products, eggs and flesh foods. For mothers with children 6-23 months, the appropriate feeding frequency for their child's age and the recommended duration of continued breastfeeding were included.

\section{Child feeding practices}

Feeding practices were assessed using a single 24-hour dietary recall of foods the child was fed in the 24 hours preceding the interview. Scores developed from the 24 hour recall were adapted from the same study conducted in Haiti [16] and based on feeding recommendations [17]. Variables for assessing feeding practices among mothers with children less than 6 months were whether the child received breast milk, formula, or semi-solid/solid foods in the preceding 24 hours. Among mothers with children 6-23 months, data on dietary diversity, feeding frequency and if the child received breast milk were obtained from the 24 hour recall.

\section{Exposure to GMP}

Mothers' exposure to GMP was assessed by how often they visited CWC. The number of months a mother had 
brought her child to the clinic in relation to the scheduled visits per the age of the child was obtained from the child's health records.

\section{Data analysis}

Data were entered and analyzed using SPSS, version 16.0. Means, standard deviation, frequencies and percentages were used to describe data.

To calculate total SES scores, individual scores ranging from 0.5 to 2.5 were given for the types of tenancy and the main sources of cooking energy. A score of 1 was given for the possession of each electrical appliance. Child feeding knowledge scores were determined by assigning a score of 1 for knowing the appropriate age of introduction of each food and appropriate feeding frequency for child's age. Scores for knowledge of the recommended duration of continued breastfeeding ranged from -2 (not knowing or indicating $\leq 6$ months) to 2 (indicating 6 to 24 months or beyond). Variables used in child feeding practice scores among mothers with children less than 6 months were whether or not a child had been fed breast milk, formula, or semi-solid/solid foods in the preceding 24 hours. A score of 1 was assigned for giving breast milk, not feeding formula and not feeding semi-solid/solid foods. Among mothers with children 6-23 months, a score of 1 was assigned for each food group fed, for feeding the recommended frequency or more and for breastfeeding.

The ratio of a child's age to the number of CWC visits attended was calculated and used in the linear regression analysis to determine the association between mother's exposure to GMP and their child feeding knowledge and practices. The proportion of age of child to number of scheduled clinics attended, the SES score, child feeding knowledge and practice scores and relevant background characteristics were included in the model.

\section{Results}

Background characteristics of participants

Of the 199 children included in the study, 98 were males and 101 were females; with a mean age of $6.78 \pm 4.65$ completed months (Table 1). The mean age for mothers was $28.09 \pm 5.31$ completed years. Most mothers had secondary level education or higher (77.4\%) and only few did not have any form of employment (17.1\%). Close to half of mothers (48.7\%) lived in a rented house and more than half used Liquefied Petroleum Gas (LPG) as their main source of energy for cooking (65.3\%). Table 1 shows the health worker as the main source of child feeding information for most mothers (58.3\%) while family and friends were indicated as a source by a little over a quarter of mothers (26.1\%).

\section{Attendance to CWC}

Table 2 shows the attendance of mothers to CWC. Seventy four percent of mothers had not missed any
Table 1 Background characteristics of mother-child pairs ( $N=199)$

\begin{tabular}{|c|c|}
\hline Characteristic & n (\%)/Mean \pm SD \\
\hline \multicolumn{2}{|l|}{ Sex of child } \\
\hline Male & $98(49.2)$ \\
\hline Female & $101(50.8)$ \\
\hline \multicolumn{2}{|l|}{ Age } \\
\hline Age of child in completed months (mean and SD) ${ }^{a}$ & $6.78 \pm 4.65$ \\
\hline Age of mother in completed years (mean and SD) ${ }^{a}$ & $28.09 \pm 5.31$ \\
\hline \multicolumn{2}{|l|}{ Marital status of mother } \\
\hline Single/widowed & $46(23.1)$ \\
\hline Married & $153(76.9)$ \\
\hline \multicolumn{2}{|l|}{ Level of education of mother } \\
\hline Primary/less ${ }^{b}$ & $45(22.6)$ \\
\hline Secondary/higher & $154(77.4)$ \\
\hline \multicolumn{2}{|l|}{ Employment status of mother } \\
\hline Unemployed & $34(17.1)$ \\
\hline Trader & $81(40.7)$ \\
\hline Artisan & $61(30.7)$ \\
\hline Domestic worker ${ }^{c}$ & $4(2.0)$ \\
\hline Professional $^{d}$ & $19(9.5)$ \\
\hline \multicolumn{2}{|l|}{ Type of accommodation } \\
\hline Caretaker & $14(7.0)$ \\
\hline Company/government & $5(2.5)$ \\
\hline Family house & $45(22.6)$ \\
\hline Rented & $97(48.7)$ \\
\hline Own & $38(19.1)$ \\
\hline \multicolumn{2}{|l|}{ Main source of cooking energy } \\
\hline Firewood & $1(0.5)$ \\
\hline Charcoal & $66(33.2)$ \\
\hline Kerosene & $1(0.5)$ \\
\hline LPG & $130(65.3)$ \\
\hline Electric cooker & $1(0.5)$ \\
\hline \multicolumn{2}{|l|}{ Household Items } \\
\hline Radio & $175(87.9)$ \\
\hline Television & $183(92.0)$ \\
\hline Refrigerator & $157(78.9)$ \\
\hline Personal Computer & $59(29.6)$ \\
\hline \multicolumn{2}{|l|}{ Source of child feeding information } \\
\hline Health worker at CWC & $116(58.3)$ \\
\hline Family and friends & $52(26.1)$ \\
\hline Self-application & $26(13.1)$ \\
\hline Information in child health records book & $3(1.5)$ \\
\hline Media sources (TV/radio/print/internet) & $2(1.0)$ \\
\hline
\end{tabular}

${ }^{a} \mathrm{SD}$, standard deviation ${ }^{\mathrm{b}}$ Less than completed Junior secondary school

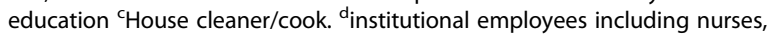
teachers, secretaries, etc. 
Table 2 CWC attendance among mothers $(\mathrm{N}=199)$

\begin{tabular}{cl}
\hline Attendance & $\boldsymbol{n}(\%) /$ Mean \pm SD \\
\hline Mean attendance & $6.09 \pm 4.3$ \\
Missed no CWC sessions & $147(73.9)$ \\
Missed one or more CWC sessions & $52(26.1)$ \\
Distribution among missed attendance & \\
Age of child (months) & \\
$0-5$ & $7(13.5)$ \\
6-8 & $24(46.2)$ \\
$9-11$ & $11(21.2)$ \\
$12-23$ & $10(19.2)$ \\
\hline
\end{tabular}

scheduled CWC sessions. Among those who had missed one or more scheduled CWC sessions, the highest percentage (46.2\%) were mothers with children aged 6-8 months, while the lowest percentage, $13.5 \%$, were mothers with children $0-5$ months.

\section{IYCF knowledge and practices}

Majority of all mothers were able to indicate the appropriate age of introduction of foods and most of those with children 6 months or older were also able to indicate the minimum number of times their child should be fed in a day (Table 3). However about a quarter of mothers indicated that vegetables, eggs and flesh foods (meat/fish/poultry/organ meats) be introduced after 8 months, while $17.1 \%$ indicated that water/other liquids be given before the child was 6 months old (Table 3).

Table 4 shows the child feeding practices of all mothers. Thirty six percent of mothers with children less than 6 months had given water to their child since birth, although a greater percentage $(80.9 \%)$ had exclusively breastfed the child in the preceding 24 hours. Among children 6 months or older, $65.5 \%$ were given water at
6 months while $20.9 \%$ were introduced to complementary foods before 6 months. Recommended feeding practices were better practiced among mothers with children below 6 months than those of older children. More than half of children above 6 months received meals from fewer than four food groups, indicating low dietary diversity. Overall, only about $32 \%$ of children aged 6-23 months received a minimum acceptable diet.

\section{Association between GMP exposure and child feeding knowledge and practices}

In linear regression analysis shown in Table 5, feeding knowledge score was positively associated with both GMP exposure and age of mother, if child was below 6 months $(p<0.05)$. Feeding practice score was also found to be significantly associated with age of the child among these mothers but not with GMP exposure. The feeding knowledge scores of mothers with children 6-23 months were not significantly associated with any of the variables in the model. In terms of feeding practices among these mothers, feeding knowledge scores were positively associated with feeding practice scores $(p<0.01)$ but was not found to have a significant relationship with GMP (Table 6).

\section{Discussion}

The study assessed the feeding knowledge and practices among mothers participating in GMP and also investigated the association between GMP exposure and mothers' child feeding knowledge and practices. In the study, a majority of mothers had not missed any CWC sessions. However among mothers who had missed one or more sessions, the highest percentage $(46.2 \%)$ was found among those with children 6-8 months. The appropriate age for introducing other foods to children was known by majority of mothers, although about a

Table 3 Mothers' knowledge of age of appropriate introduction of foods and feeding recommendations among children 0-23 months ( $N=199)$

\begin{tabular}{|c|c|c|c|c|}
\hline \multirow{3}{*}{ Foods } & \multicolumn{4}{|c|}{ Age indicated (months) } \\
\hline & $\overline{<6}$ & $6-8^{a}$ & $>8$ & Not sure \\
\hline & $n(\%)$ & $n(\%)$ & $n(\%)$ & $n(\%)$ \\
\hline Water/other liquids & $34(17.1)$ & $163(81.9)$ & $2(1.0)$ & $0(0.0)$ \\
\hline Staples (grains, roots \& tubers) & $13(6.5)$ & $174(87.4)$ & $10(5)$ & $2(1.0)$ \\
\hline Vegetables & $8(4.0)$ & $136(68.3)$ & $45(22.6)$ & $10(5.0)$ \\
\hline Fruits & $10(5.0)$ & $153(76.9)$ & $30(15.1)$ & $6(3.0)$ \\
\hline Dairy products & $11(5.5)$ & $154(74.9)$ & $27(13.6)$ & $12(6.0)$ \\
\hline Eggs (yolk \& whole) & $4(2.0)$ & $141(70.9)$ & $50(25.1)$ & $4(2.0)$ \\
\hline Flesh foods (meat/fish/poultry/organ meats) & $4(2.0)$ & $133(66.8)$ & $56(28.1)$ & $6(3.0)$ \\
\hline Knows minimum number of times to feed child in a day ${ }^{\dagger} \mathrm{b} n(\%)$ & $95(86.4)$ & & & \\
\hline Knows recommended duration of continued breastfeeding ${ }^{\dagger}{ }^{c} n(\%)$ & $62(56.4)$ & & & \\
\hline
\end{tabular}

${ }^{\dagger}$ Values for these variables are for mothers with children $\geq 6$ months. ${ }^{\mathrm{a}}$ Recommended age for introduction of foods in addition to breast milk [17]. ${ }^{\mathrm{b}}$ Twice/more for breastfed infants 6-8 months, 3 times/more for breastfed children 9-23 months and 4 times/more for non-breastfed children 6-23 months [17]. ${ }^{c} \geq 24$ months [17]. 
Table 4 Child feeding behaviour reported by mothers of children 0-23 months ( $N=199)$

\begin{tabular}{|c|c|}
\hline Feeding & n (\%) \\
\hline \multicolumn{2}{|l|}{ Children $<6$ months $(n=89)$} \\
\hline \multicolumn{2}{|l|}{ Introduction of water (since birth) } \\
\hline Started & $32(36.0)$ \\
\hline Not yet & $57(64.0)$ \\
\hline \multicolumn{2}{|l|}{ Feeding practices in the preceding 24 hours } \\
\hline Exclusive breastfeeding & $72(80.9)$ \\
\hline Breast milk and formula & $5(5.6)$ \\
\hline Breast milk and complementary foods & $6(6.7)$ \\
\hline Not receiving any breast milk & $6(6.7)$ \\
\hline
\end{tabular}

Children $\geq 6$ months $(n=110)$

Age of introduction of water

$\begin{array}{ll}<6 \text { months } & 38(34.5) \\ \text { At } 6 \text { months } & 72(65.5)\end{array}$

Age of introduction of complementary foods

$<6$ months

$23(20.9)$

At 6 months

$87(79.1)$

Feeding practices in the preceding 24 hours

Fed grains, roots and tubers

Fed legumes and nuts

Fed dairy products

$53(48.2)$

Fed flesh foods (meat/fish/poultry/organ meats)

Fed eggs

8 (7.3)

Fed vitamin A rich fruits and vegetables

$36(32.7)$

Fed other fruits and vegetables

$58(52.7)$

Met dietary diversity/more

$46(41.8)$

Met adequate feeding frequency ${ }^{b}$

$70(63.8)$

Met minimum acceptable diet ${ }^{\complement}$

35 (31.8)

Breastfed

$100(90.9)$

${ }^{\mathrm{a}}$ Consumption of meals containing 4 or more food groups (PAHO/WHO, [17].

${ }^{b} 2$ times/more for breastfed infants 6-8 months, 3 times/more for breastfed

children 9-23 months and 4 times/more for non-breastfed children 6-23 months [17].

${ }^{c}$ Fed foods meeting the recommended minimum dietary diversity and the minimum feeding frequency [17].

quarter indicated wrong timing for introduction of vegetables, eggs and flesh foods. Feeding practices in the preceding 24 hours was appropriate among children 0-5 months compared to children 6-23 months. Exclusive breastfeeding (EBF) was practiced by $80.1 \%$ of mothers with children 0-5 months in the preceding 24 hours. In children 6-23 months over half of them did not receive a minimum acceptable diet in the previous day. GMP exposure was found to be associated with feeding knowledge of mothers with children 0-5 months old.

The ability of mothers to practice recommended feeding practices has been associated with maternal nutrition knowledge $[18,19]$. Thus it might be expected that
Table 5 Factors associated with child feeding knowledge among mothers $(\mathrm{N}=199)$

\begin{tabular}{llll}
\hline Variable & $\begin{array}{l}\text { Regression } \\
\text { coefficient }\end{array}$ & P-value & $\mathbf{R}^{2}$ \\
\hline
\end{tabular}

Mothers with children $<6$ months

$(n=89)$

Feeding knowledge score

$\begin{array}{lll}\text { Age of mother } & .250 & .019 \\ \text { Level of education of mother } & .061 & .556 \\ \text { Age of child/number } & .225 & .034\end{array}$

attended (proportion)

Mothers with children 6-23 months

$(n=110)$

Feeding knowledge score

\begin{tabular}{llll} 
Age of mother & .132 & .172 & \\
Level of education of mother & .076 & .434 & $.000^{*}$ \\
$\begin{array}{l}\text { Age of child/number attended } \\
\text { (proportion) }\end{array}$ & .043 & .656 & \\
\hline
\end{tabular}

with over $80 \%$ of mothers in this study indicating the appropriate age of introduction of water/other liquids, a similar trend will be seen in the practice of EBF. However, having knowledge alone may not always result in best practices [8]. Similar to results found by previous studies in Nigeria and Ghana [19-21], a contradiction was observed between mothers' knowledge and practice of EBF. The results from this study show that fewer mothers practiced EBF from birth, as indicated by the

Table 6 Factors associated with child feeding practices among mothers $(N=199)$

\begin{tabular}{llll}
\hline Variable & $\begin{array}{l}\text { Regression } \\
\text { coefficient }\end{array}$ & P-value & $R^{2}$ \\
\hline
\end{tabular}

Mothers with children $<6$ months $(n=89)$

Feeding practice score

$\begin{array}{lll}\text { Age of mother } & .099 & .354 \\ \text { Age of child } & -.352 & .001 \\ \text { Level of education of mother } & -.071 & .540 \\ \text { Socioeconomic score } & -.065 & .576 \\ \text { Feeding knowledge } & .172 & .105 \\ \text { Age of child/number attended } & .033 & .764\end{array}$

Mothers with children 6-23 month $(n=110)$

Feeding practice score

$\begin{array}{lcc}\text { Age of mother } & -.114 & .242 \\ \text { Age of child } & .179 & .069 \\ \text { Level of education of mother } & .132 & .174 \\ \text { Socioeconomic score } & .011 & .911 \\ \text { Feeding knowledge } & .273 & .004 \\ \begin{array}{l}\text { Age of child/number attended } \\ \text { (proportion) }\end{array} & .066 & .479 \\ \end{array}$


introduction of water/other liquids, than was shown by the 24 hour recall and this is comparable to findings in a study on EBF in Ghana [20]. This contrast between knowledge and practices may be attributed to barriers such as maternal employment, maternal health, cultural beliefs and practices and social pressure from family and friends [13,19,22-24].

The transition from EBF to CF is associated with several challenges in developing countries, including infrequent feeding, low energy and less nutrient dense foods, poor food storage and sanitation and food taboos [9,22,23]. These constraints make the nutritional and energy requirements of the growing child difficult to meet, making undernutrition more likely during this period [25]. Generally, feeding practices among children less than 6 months were shown to be better in the preceding 24 hours than were found for CF practices. Most children were fed meals made from grains, roots and tubers than from other foods in the preceding 24 hours as found in the Ghana Demographic and Health Survey [10]. Comparable to the Multiple Indicator Cluster Survey in Ghana [4], more children aged 6-23 months were fed the minimum recommended times or more in a day than were fed dietary diverse diets, with few meeting the minimum acceptable diet. The implication of this is that, nutrient requirements may not have been met in over half of the children in this study. To ensure that complementary feeding practices are adequate for optimal child growth from 6 months, accurate and consistent information and skilled support are essential as are for EBF [1]. It has been said that 'Considerable global and national efforts and attention have been devoted to breastfeeding promotion to the neglect of complementary feeding practices' [8].

As the results of this study have shown, health services remain a major source of child feeding information for mothers [13,26,27]. It is expected that, the consistent monthly interaction between mothers and health workers as part of the GMP will provide not only knowledge, but also the support mothers need to undertake recommended feeding practices. Mothers' exposure in GMP was positively associated with the feeding knowledge scores of mothers with children less than 6 months but not on their feeding practices. This emphasises the need for repeated supportive counselling rather than the relaying of only breastfeeding messages $[8,20,28]$. Exposure to GMP was not found to be associated with child feeding knowledge or practices among mothers with children 6 months or older. This may draw attention again to the less attention given to CF [8]. However for these mothers', knowledge of child feeding recommendations was seen to have a positive association with feeding practices. An implication that if much attention is given to complementary feeding counselling and support during GMP sessions an impact will be seen in feeding practices and subsequently on child nutritional status.
In areas where nutrition counselling which is ageappropriate and specific to the family environment has been offered through the health system, improvements in the knowledge of mothers and the diets of children have been observed [27-31]. Mothers find it difficult to practice what they are told when messages are nonspecific with less attention to a mother's household condition or availability of foods [1,32]. However, most CWC visited during this study offered no or generic nutrition messages and even fewer were observed to have group counselling sessions conducted by a nutritionist or community health nurse on some of the clinic days. Such nutrition messages that are non-age specific and non-individualized during GMP have been observed in other developing countries [33-35]. These practices do not enable the GMP programme to effectively improve mothers' knowledge and practices for better child growth outcomes [11,12]. The poor delivery of counselling has been attributed to a lack of required knowledge and skills on the part of health workers, heavy demand relative to personnel, lack of incentives and motivation, inadequate supervision, uncooperative and mistrusting mothers $[12,27,35,36]$.

\section{Study limitations}

Results in this study may not be generalizable to other regions as the study was conducted only in the Greater Accra Region which may differ from other regions in socio-demographic characteristics of respondents and health facility characteristics. Also in assessing knowledge, caregivers may speculate correct answers which may show good scores but may not reflect reality.

\section{Conclusion}

Results from this study indicate that although most mothers participating in GMP in the AMA of Ghana were knowledgeable about child feeding recommendations, feeding practices were suboptimal, especially among children receiving complementary feeding. GMP exposure was, however, not associated with child feeding knowledge and practices; an exception was the association between GMP exposure and practices of mothers with children under 6 months. For the GMP programme to realize its objectives of improving child growth through influencing care and feeding practices, the nutrition counselling and support, should be strengthened among mothers of children receiving complementary feeding.

\section{Competing interests}

The authors declare that they have no competing interests.

\section{Authors' contributions}

SG conceived the study, participated in study design, prepared study tools, collected and analyzed data and prepared the manuscript. GEO supervised the study, participated in study design, finalizing study tools, data analysis and critically revising the manuscript. RA supervised the study, participated 
in study design, finalizing study tools, data analysis and critically revising the manuscript. All authors read and approved the final manuscript.

\section{Authors' information}

SG (MPhil) is a recent graduate of the Department of Nutrition and Food Science, University of Ghana, Legon. GEO (PhD) is a lecturer at the Department of Nutrition and Food Science at the University of Ghana, Legon. RA (MPH, PhD) is a Senior Lecturer at the Population, Family and Reproductive Health Department at the School of Public Health of the University of Ghana.

\section{Acknowledgements}

Authors would like to acknowledge the Ghana Health Service, Accra Metropolitan area and all health facilities and mothers who participated in this study.

\section{Author details}

'Department of Nutrition and Food Science, University of Ghana, Legon, P.O. Box LG 134, Accra, Ghana. ${ }^{2}$ School of Public Health, University of Ghana, Legon, P.O. Box LG 13, Accra, Ghana.

\section{Received: 7 August 2013 Accepted: 21 May 2014}

Published: 29 May 2014

\section{References}

1. WHO/UNICEF: Global Strategy for Infant and Young Child Feeding. Geneva: World Health Organization; 2003 [http://whqlibdoc.who.int/publications/ 2003/9241562218.pdf]

2. Black RE, Allen LH, Bhutta ZA, Caulfield LE, Onis M, Ezzati M, Mathers C, Rivera J: Maternal and child undernutrition: global and regional exposures and health consequences. Lancet 2008, 371:243-260.

3. Katona $\mathrm{P}$, Katona-Apte J: The interaction between nutrition and infection Clin Infect Dis 2008, 46:1582-1588.

4. Ghana Statistical Service (GSS): Ghana Multiple Indicator Cluster Survey with an Enhanced Malaria Module and Biomarker. Accra, Ghana: Ghana Statistical Service; 2011.

5. Ruel MT, Levin CE, Armar-Klemesu M, Maxwell D, Morris SS: Good care practices can mitigate the negative effects of poverty and low maternal schooling on children's nutritional status: evidence from Accra. World Dev 1999, 27:1993.

6. Ruel MT, Menon P: Child feeding practices are associated with child nutritional status in Latin America: Innovative uses of the demographic and health surveys. J Nutr 2002, 132:1180-1187.

7. Appoh LY, Krekling S: Maternal nutrition knowledge and child nutritiona status in the Volta Region of Ghana. Matern Child Nutr 2005, 1:100-110.

8. Lartey A: Maternal and child nutrition in Sub-Saharan Africa: challenges and interventions. Proc Nutr Soc 2008, 67:105-108.

9. Dewey KG, Adu-Afarwuah S: Systematic review of the efficacy and effectiveness of complementary feeding interventions in developing countries. Matern Child Nutr 2008, 4:24-85.

10. Ghana Statistical Service (GSS), Noguchi Memorial Institute for Medical Research (NMIMR), and ORC Macro: Ghana Demographic and Health Survey 2003. Calverton, Maryland: GSS, NMIMR, ORC Macro; 2004

11. UNICEF: Revisiting growth monitoring and its evolution to promoting growth as a strategic program approach: building consensus for future program guidance. Report of the technical consultation on growth monitoring and promotion. In Book Revisiting Growth Monitoring and Its Evolution to Promoting Growth as a Strategic Program Approach: Building Consensus for Future Program Guidance. Report of the Technical Consultation on Growth Monitoring and Promotion. New York: UNICEF; 2007.

12. Ashworth A, Shrimpton R, Jamil K: Growth monitoring and promotion: review of evidence of impact. Matern Child Nutr 2008, 4:86-117.

13. Otoo GE, Lartey A, Pérez-Escamilla R: Perceived incentives and barriers to exclusive breastfeeding among periurban Ghanaian women. J Hum Lact 2009, 25:34-41.

14. Owusu WB, Lartey A: Growth monitoring: experience from Ghana. Food Nutr Bull 1992, 14:97-100.

15. Cochran WG: Sampling Techniques. 2nd edition. New York: John Wiley and Sons Inc: 1963.

16. Menon P, Ruel M: Child care, nutrition and health in the central plateau of Haiti: The role of community, household and caregiver resources. Report of the IFPRI-Cornell World Vision Baseline Survey, Haiti 2002. A report submitted to the
Food and Nutrition Technical Assistance Project. Washington, D.C: Academy for Educational Development; 2003 [http://www.fantaproject.org/ sites/default/files/resources/IFPRI_R8_1003.pdf]

17. PAHO/WHO: Guiding Principles for Complementary Feeding of the Breastfed Child. Washington D.C: Pan American Health Organization/World Health Organization; 2003 [http://whqlibdoc.who.int/paho/2003/a85622.pdf]

18. Aidam BA, Perez-Escamilla R, Lartey A: Lactation counselling increases exclusive breast-feeding rates in Ghana. J Nutr 2005, 135:1691-1695.

19. Kimani-Murage EW, Madise NJ, Fotso J-C, Kyobutungi C, Mutua MK, Gitau TM, Yatich N: Patterns and determinants of breastfeeding and complementary feeding practices in urban informal settlements, Nairobi Kenya. BMC Public Health 2011, 11:369.

20. Aidam BA, Perez-Escamilla R, Lartey A: Factors associated with exclusive breastfeeding in Accra, Ghana. Eur J Clin Nutr 2005, 59:789-799.

21. Agunbiade OM, Ogunleye OV: Constraints to exclusive breastfeeding practice among breastfeeding mothers in Southwest Nigeria: Implications for scaling up. Int Breastfeed J 2012, 7:5.

22. Kruger R, Gericke GJ: A qualitative exploration of rural feeding and weaning practices, knowledge and attitudes on nutrition. Public Health Nutr 2003, 6:217-223.

23. Gyimah SO: Cultural background and infant survival in Ghana. Ethn Health 2006, 11:101-120.

24. Kerr RB, Berti PR, Chirwa M: Breastfeeding and mixed feeding practices in Malawi: Timing, reasons, decision makers, and child health consequences. Food Nutr Bull 2007, 28:90-99.

25. Shrimpton R, Victora CG, Onis M, Lima RC, Blossner M, Clugston G: Worldwide timing of growth faltering: implications for nutritional interventions. Pediatrics 2001, 107:e75.

26. McLorg PA, Bryant CA: Influence of social network members and health care professionals on infant feeding practices of economically disadvantaged mothers. Med Anthropol 1989, 10:265-278.

27. Pelto GH, Santos I, Goncalves H, Victora C, Martines J, Habicht J-P: Nutrition counseling training changes physician behavior and improves caregiver knowledge acquisition. J Nutr 2004, 134:357-362.

28. Haque MF, Hussain M, Sarkar AK, Hoque MM, Ara FA, Sultana S: Breast-feeding counselling and its effect on the prevalence of exclusive breast-feeding. J Health Popul Nutr 2002, 20:312-316.

29. Santos I, Victora CG, Martines J, Goncalves H, Gigante DP, Valle NJ, Pelto G Nutrition counseling increases weight gain among Brazilian children. J Nutr 2001, 131:2866-2873

30. Penny ME, Creed-Kanashiro HM, Robert RC, Narro MR, Caulfield LE, Black RE: Effectiveness of an educational intervention delivered through the health services to improve nutrition in young children: a clusterrandomised controlled trial. Lancet 2005, 365:1863-1872.

31. Zaman S, Ashraf RN, Martines J: Training in complementary feeding counselling of healthcare workers and its influence on maternal behaviours and child growth: a cluster randomized controlled trial in Lahore, Pakistan. J Health Popul Nutr 2008, 26:210-222.

32. IYCN: Summary of Sociocultural and Epidemiological Findings on Infant and Young Child Feeding in 11 Countries. Washington D. C: USAID's Infant \& Young Child Nutrition Project; 2011 [http://www.iycn.org/files/ IYCN_summary_sociocultural_findings_083011.pdf]

33. Gerein NM, Ross DA: Is growth monitoring worthwhile? An evaluation of its use in three child health programmes in Zaire. Soc Sci Med 1991 32:667-675.

34. Ruel MT, Habicht JT, Olson C: Impact of a clinic-based growth monitoring programme on maternal nutrition knowledge in Lesotho. Int J Epidemiol 1992, 21:59-65.

35. Charlton KE, Kawana BM, Hendricks MK: An assessment of the effectiveness of growth monitoring and promotion practices in the Lusaka district of Zambia. Nutrition 2009, 25:1035-1046.

36. Roberfroid D, Kolsteren P, Hoeree T, Maire B: Do growth monitoring and promotion programs answer the performance criteria of a screening program? A critical analysis based on a systematic review. Trop Med Int Health 2005, 10:1121-1133.

\section{doi:10.1186/1471-2393-14-180}

Cite this article as: Gyampoh et al:: Child feeding knowledge and practices among women participating in growth monitoring and promotion in Accra, Ghana. BMC Pregnancy and Childbirth 2014 14:180. 